DOI: $10.17516 / 1997-1370-0705$

УДК 81 '234.2

\title{
Speech Disorders Testing: Practices of European and Russian Clinical Linguistics
}

\author{
Natalia G. Burmakina, Iuliia I. Detinko, \\ Liudmila V. Kulikova and lana V. Popova* \\ Siberian Federal University \\ Krasnoyarsk, Russian Federation
}

Received 11.08.2020, received in revised form 11.09.2020, accepted 10.12.2020

\begin{abstract}
The article is devoted to the problem of speech disorders caused by local brain damage. The purpose of the study is to demonstrate different tests for diagnosing aphasia developed in European countries and Russia. Four out of these methods have passed significant approbation and are widely used for testing the speech of the patients with aphasia. The other three were created recently and reflect current data from neurolinguistics. The authors used a descriptive method to present the testing systems. The study showed that European classifications of aphasia differ from Russian ones. There is a problem of discrepancies in diagnosis when using different methods. It was noted that there is a culturally specific marker of diagnosis in accordance with the research traditions of different countries and cognitive and mental characteristics of the patients who speak different languages. Modern approaches to working with aphasia are associated with neuropragmatics, research of metalinguistic abilities and augmentative / alternative communication. The prospects for diagnosing speech localization in the brain are found in the combination of methods of neuropsychology and neuroimaging and in the use of artificial intelligence. The problem of post-stroke speech disorders is relevant and requires the combined efforts of speech therapists, linguists, neurologists, and neuropsychologists.
\end{abstract}

Keywords: clinical linguistics, aphasia, methods of neuropsychological diagnostics, Aachen Aphasia Test, Western Aphasia Battery, Scenario Test, Protocol of Metalanguage in Aphasia, speech rehabilitation.

Research area: linguistics.

Citation: Burmakina, N.G., Detinko, Iu.I., Kulikova L.V., Popova, Ia.V. (2020). Speech disorders testing: practices of European and Russian clinical linguistics. J. Sib. Fed. Univ. Humanit. Soc. Sci., 13(12), 1973-1984. DOI: 10.17516/1997-1370-0705.

\footnotetext{
(C) Siberian Federal University. All rights reserved

* Corresponding author E-mail address: nburmakina@mail.ru, julia detinko@mail.ru, info_ifiyak@sfu-kras.ru, yanapopov@ yandex.ru

ORCID: 0000-0003-2102-4258 (Burmakina); 0000-0001-8254-8085 (Detinko); 0000-0002-1622-8304 (Kulikova); 0000-0001-9435-8617 (Popova)
} 


\section{Introduction}

The recovery of the ability for verbal communication, lost as a result of disorder in the functioning of certain areas of the brain that provide speech activity, remains an urgent task today. An increase in average life expectancy leads to an increase in the frequency of strokes, which makes the problem of rehabilitation of patients with disorders of higher mental functions important. Every year in the world more than 6 million people suffer a stroke, in Russia - more than 450 thousand (Kadykov, Shakhparonova, 2013: 76). Researchers note that $25-30 \%$ of strokes are accompanied by aphasias of varying severity (Mozheiko, 2008: 16).

In this work, we propose the analysis of aphasiological tests used in European countries and in Russia to study speech disorders caused by cerebrovascular accidents.

The article presents four European and three Russian tests. Luria's methods of neuropsychological diagnostics, the method of assessing the dynamics of speech in the patients with aphasia developed by L.S. Tsvetkova, the Aachen Aphasia Test and the Western Aphasia Battery were created in the $40 \mathrm{~s}-80$ s of the last century and have been widely used for testing the speech of people with aphasia. The complex of neuropsychological tests by Wasserman et al., Scenario Test and Protocol of Metalanguage in Aphasia reflect new directions in the search for effective tools to examine patients with speech disorders.

\section{Description of the tests}

Luria's methods of neuropsychological diagnostics were developed by the Soviet psychologist A.R. Luria (Luria, 2021). For the first time, the description of the method of clinical-psychological examination was published in 1947 and was the result of the author's work on practical and theoretical problems which Soviet neurology faced during the Great Patriotic War due to a large number of craniocerebral wounds (Luria, 1947). The methods created for the localization diagnosis of cerebral injuries caused by military traumas were refined in the following decades and successfully tested in other areas: to study the cerebral organization of mental functions, to identify the deficit in the work of certain brain areas, to diagnose the condition of various brain structures (Neuropsychological diagnostics, 2007: 4).

The test allows identifying various types of aphasiac syndrome: sensory aphasia (the primary defect is the distinction of phonemes), acoustic-mnestic (impairment of auditory-speech memory), semantic (difficulties in choosing words according to meaning and in understanding logical-grammatical constructions), afferent motor aphasia (errors in the choice of the elementary sounds), efferent motor aphasia (impairment of the kinetic organization of speech, difficulties in grammatical structuring) and dynamic aphasia (impairment of verbal planning and verbal activity) (Ardila et al., 2020: 6).

The study is preceded by a short description of the patient's clinical chart and talk to the patient to draw general characteristics of the testee (state of consciousness, mental activity, complaints, orientation in place and time, reaction to disorientation, criticality towards himself, his illness and other people, state of emotional sphere). This is followed by the assessment of the lateral organization of functions (manual, visual, and auditory-speech asymmetry are revealed). The examiner tests involuntary and voluntary attention, visual and visual-spatial gnosis (recognition of real objects: realistic and schematic, crossed out and conflicting images; the volume of visual perception; recognition of faces, colors; constructive activity; dividing the line to identify asymmetry; identifying the side neglect; letter and digital gnosis) and somatosensory gnosis (tests for the localization of touches, determining the number of touches, assessing skin-kinesthetic sensations, transferring the pose of one hand to the other with closed eyes, determining the right and left sides, naming fingers, recognizing objects by touch). The next stage includes the study of auditory gnosis and auditory-motor coordination (performing instructions alternately with the right and left hand, manual praxis, Head's tests, dynamic praxis, reciprocal coordination, asymmetric tapping, graphic tests, study of constructive praxis, drawing, performing actions with objects, 
symbolic praxis, eye movement analysis, oral praxis, conditioned responses).

The study of speech includes testing the ability to speak spontaneously, testing automated speech, disautomated speech, reflected speech, naming of the objects, understanding of the addressed speech and expanded spontaneous utterances.

The next two sections are aimed at testing the retention of writing (automated writing; writing at dictation; copying letters, words and phrases) and reading (letters, syllables, ideograms, frequent and rare words, phrases).

Further, the state of memory is studied (memorizing a series of numbers, direct and delayed repetition of words, memorizing a series of 10 words, memorizing and delayed reproduction of groups of words, semantic series; memorizing and retelling two short narratives).

Then, the retention of the counting system is studied (counting, reading numbers, reading and writing complex numbers, performing counting operations of varying complexity).

The test is finished by diagnostics of intellectual processes (examining the ability to perceive the content of a story, a picture with a plot, to do arithmetic tasks, to complete a phrase with a highly probable word, to fill in missing words in a phrase, to name associative rows, antonyms, to select analogies; to perform logical tasks with words, to compare proverbs and their explanations) and the study of the emotional sphere.

Based on the study, the examiner draws a qualitative conclusion, formulates the characteristics of the syndrome and determines the localization of the lesion.

Luria's methods of neuropsychological diagnostics, developed on the basis of fundamental scientific ideas about the cerebral organization of human mental functions, makes it possible to achieve a high accuracy of the localization diagnosis, gives the opportunity not only to state the presence and severity of higher mental functions disorders but also to determine their qualitative specificity.

Method of assessing the speech dynamics in the patients with aphasia. The method was developed by L.S. Tsvetkova, a representative of the neuropsychological scientific school of Moscow University, A.R. Luria's student. The purpose of the test is to determine the severity of speech disorders, to measure the effectiveness of speech restoration in the patients with aphasia and to assess the effectiveness of the applied methods of restorative teaching (Tsvetkova, 1988: 129). The work has been widely used in various rehabilitation centers in Moscow and other cities. The method is based on the classification of aphasiac disorders developed by A.R. Luria.

The method includes two series of tasks: tests for expressive speech (assessment of productive speech skills) and for impressive speech (assessment of receptive speech skills). On completion of each task, the testee receives a certain number of points. An increase in the total number of points in the subsequent testing indicates progress in overcoming the defect and the effectiveness of restorative teaching.

The control of expressive speech begins with the study of the testee's dialogic skills. The patient is asked to answer ten questions of different structure: alternative, open, requiring a detailed answer. The examiner takes into account not only the adequacy of the answer to the question, but also the quality of speech production. The score decreases if there are literal paraphasias, echolalia, excessive wordiness, grammatically incorrect speech and inaccurate answers.

This is followed by testing the ability to find a nomination for objects or actions. It helps to identify the retention of the ability to match linguistic units with the designated objects. The testee is presented with a series of thirty pictures, he must name the objects or actions depicted in them. First, there are monosyllabic or disyllabic lexemes with alternating vowels and consonants, then images are presented, the nomination of which requires pronouncing polysyllabic words containing a cluster of consonants. When evaluating the answers, the examiner takes into account the quality of pronunciation, the presence of literal paraphasias, and the ability to complete the task using contextual prompts.

The third task is aimed at controlling phrasal speech. The testee is presented with images, which he must comment on with detailed 
phrases. Samples are presented in the order of increasing difficulty. When assessing, the number of points decreases if the testee omits the subject of the sentence, uses an unusual word order, demonstrates verbal paraphasias, chooses an incorrect tense of the verb.

The fourth task controls the ability to construct a detailed statement, the visual stimulus for which serves the reproduction of F.P. Reshetnikov's picture "A bad mark again".

The next step is a series of tests to assess impressive speech.

The first task tests the ability to understand the addressed speech in the dialogue. The testee is presented with a series of questions of varying difficulty. The criteria for simplicity / complexity are the number of words in the question, the use of simple syntactic models, the frequency of using these questions in the situations of communication with the patient, for example: "Do you have a headache?" The answer is also counted when the gesture is used.

The second test allows checking the testee's understanding of the meanings of individual words (verbs and nouns). The patient is presented with a series of pictures: from each series he must select and show those that correspond to the pronounced words. All samples are ranked in terms of difficulty: the first group includes frequency words that are not similar in sound and do not belong to the same category, for example, "cat, cheese, bag"; the second group consists of medium frequency words similar in sound "bad - bat, tan - ton"; the third group unites the words included in one semantic field "stockings, socks, mittens". The author notes that the task allows fixing not only an acoustic analysis disorder and auditory speech traces retention, but also the difficulty in semantic differentiation of words (Tsvetkova, 1988: 134). If it is impossible to complete the task from the first presentation, repetition is possible, but the number of points decreases.

This is followed by testing the ability to understand sentences. The testee is presented with a series of images and a stimulus phrase is pronounced; the patient must choose a picture that is suitable in meaning. Each trial becomes more complicated due to the increase in the number of presented images and the convergence of semantic elements in the images, also due to the inclusion of prepositional and passive constructions. A person's ability to decode utterances is influenced by both linguistic characteristics (the complexity of lexical units, the complexity of the syntactic model, the volume of the sentence, intonation) and psychological factors (the closeness of the topic of the sentence to the listener, emotional attitude to the message). The assessment takes into account the number of presentations of speech material.

The last task is aimed at testing comprehension of verbal instructions. The testee is given a series of ten instructions that he must follow: "Close your eyes", "Put the pen to the right of the book". In each subsequent test, the volume and grammatical complexity of the statements increase. If the instructions are repeated, the number of points is reduced. If an error is made and corrected by the testee himself, the score does not decrease.

The Aachen Aphasia Test (Der Aachener Aphasie-Test (AAT)) was developed in 1983 at Rhine-Westphalian Technical Aachen University by W. Huber, K. Poeck, D. Weniger and K. Willmes (Huber et al., 1983). The test is widely used among speech therapists, clinical linguists and physicians in Germany and other German-speaking countries; later the versions were developed for English (Miller et al., 2000), Portuguese (Lauterbach et al., 2008) and other European languages.

The test allows the examiner to identify the presence of aphasia; diagnose one of the four types of aphasiac syndrome (global aphasia, Broca's aphasia, Wernicke's aphasia, amnestic aphasia); identify the presence of non-classified aphasia and other speech disorders; assess the severity of the defect (light, moderate, severe); perform a comparative analysis in the dynamics of speech rehabilitation.

The test includes six sections that analyze the severity of the speech disorder. The success of each test is rated on a scale from zero to three.

The first section controls the ability for spontaneous verbal communication (spontaneous language rating). The examiner asks a series of open-ended, person-centered ques- 
tions. The topics of the questions are family, profession and others; on the basis of these questions the adequacy of communicative behavior, articulation, prosodic characteristics, the use of linguistic automatisms, the correctness of semantic and syntactic structures are tested. The examiner fixes the presence of echolalia, lexical and verbal paraphasias, repetitions, speech tempo and the latency period for the search of the necessary nominations.

The next subtest is aimed at monitoring the understanding of sounding speech, the ability to concentrate, and the retention of cognitive abilities (token test). The testee is presented with a number of geometric figures of different colors, he must show certain figures of a particular color, following oral instructions. The rating scale includes two options: right / wrong. This subtest reveals the presence of disorders comorbid with aphasia.

The third subtest looks at the ability for reflected speech (repetition). The testee must repeat isolated sounds, monosyllabic words, words of foreign origin, compound words, and whole sentences. The quality of pronunciation is taken into account.

The fourth subtest controls the writing skills (written language). The testee is asked to read individual lexemes and sentences aloud; he composes words and statements from the elements printed separately, writes at dictation. A total number of tasks is 10 .

The next subtest is aimed at identifying the syndrome of nominative difficulties (naming). The testee is asked to perform a series of tests - name the depicted object, color, make a sentence to a visual stimulus, describe the situation illustrated in the picture. Each subsequent test stimulates the performance of more complex speech production.

The sixth subtest is aimed at checking the understanding of speech (comprehension). The testee is offered a series of four images, he must choose a picture that corresponds to the verbally presented word or sentence. In total, the subtest includes ten series of images.

The results of the token test and the writing test are collectively visualized in a graph and are used to diagnose the presence of aphasia and the severity of the defect. Further, the scores obtained for each of the subtests are compared with specially designed scales, which makes it possible to diagnose the type of aphasia. The computer program ALLOC is used to evaluate the results.

The Western Aphasia Battery (WAB) was developed by the British aphasiologist E. Kertes at the Center for Cognitive Neurology and Alzheimer's Disease Research at St. Joseph's Hospital in London, the first materials about its use were published in 1982 (Risser, Spreen, 1985).

The battery of tests is used in work with English-speaking patients, allowing the examiner to diagnose the presence, type and severity of aphasia, to make a localization diagnosis; it is also used to assess the effectiveness of speech restoration.

The Western Aphasia Battery is directed at the classification of the following types of aphasia: global; Broca; isolation, transcortical sensory; associative; amnestic; transcortical motor; Wernicke; mixed; unclassified.

The battery includes the subtests that assess the information content of the patient's speech, fluency, listening ability, reflected speech, naming of the objects, reading, writing, non-verbal abilities: drawing, visual thinking, praxis.

The test begins with the assessment of the ability to speak spontaneously, which is tested by six general questions ("How are you today?" "What is your occupation?" and others) and the description of the image of a genre fragment ("Tell me what you see", "Try to talk in sentences"). If the description is too laconic, the testee is asked to express himself in more detail. The received responses are analyzed to assess the content ( $0-10$ points). The examiner takes into account how many questions were answered, the complexity and depth of the sentences when describing the image. Also, this task is used to assess the fluency of speech $(0$ to 10 points).

Listening comprehension is tested by 20 alternative questions related to personality orientation, environment, and general knowledge ("Is your name Smith?" "Is the door closed?" "Is a horse larger than a dog?"). When answering alternative questions, it is sufficient for the 
testee to use the appropriate gesture. The retention of word recognition is also tested. The examiner uses the cards showing the images of objects, numbers, letters, body parts, geometric figures. Recognition of words is tested by pointing to the required image or real object. The examiner pronounces the task ("Show me the ..."). When naming body parts, the task becomes more difficult, the testee must choose correctly between the right and left leg, arm, etc. The next task is to perform the pronounced commands ("Shut your eyes", "Put the pen on top of the book then give it to me").

The ability for the reflected speech is tested through the presentation of 15 subtests, the first of which is represented by one word, the last by a complex sentence unnatural for the language. The examiner considers the articulatory correctness of the testee's reactions.

The test for nominative difficulty includes naming of the objects (animals), completing sentences and answering the questions. In case of gross alienation of the meaning of the word, the testee is provided with support.

The execution of the above linguistic tests takes on average 1.5 hours. Other skills are tested in a separate session where reading, writing, the retention of non-linguistic cognitive abilities (drawing, counting, choosing the correct geometric pattern) and praxis are taken into account.

Reading assignments include performing reading commands, matching written words and images, recognizing letters.

Completing all the subtests results in a total of 100 points. The number of points from 76 and above indicates light, 51-75 moderate, 26-50 severe, 0-25 extremely severe aphasia. The result of 93 or more points indicates that the testee has no aphasia.

Complex of neuropsychological tests by L.I. Wasserman et al. The complex of neuropsychological tests was developed by a team of researchers who were the students of professor N.N. Traugott and professor I.M. Tonkonogii. The tests passed the approbation in the laboratory of clinical psychology and psychiatric diagnostics in V.M. Bekhterev Institute and other medical institutions in St. Petersburg and were published in 1997 (Wasserman et al., 1997).
Neuropsychological methods are used for solving the problems of localization diagnosis of focal brain lesions, assessing the severity of defects, and conducting a comparative analysis in the dynamics of rehabilitation treatment of patients with aphasia.

The classification of aphasias adopted by the authors is based on A.R. Luria's psychophysiological typology and I.M. Tonkonogii's clinical typology. It includes the following types: efferent (verbal) motor aphasia, dynamic aphasia, afferent (articulatory) motor aphasia, acoustic-gnostic (sensory-acoustic) sensory aphasia, acoustic-mnestic (sensory-amnestic) aphasia, amnestic aphasia, semantic aphasia, conduction aphasia, mixed (complex) motor aphasia, mixed sensory-efferent motor aphasia (combination of efferent motor and sensory acoustic-gnostic aphasia), mixed sensory-afferent motor aphasia (combination of afferent motor and sensory acoustic-gnostic aphasia), total aphasia, speech-auditory agnosia, speech disorder with damage to the right hemisphere.

The complex of neuropsychological tests is used in two versions: full and reduced. The reduced version is used for express diagnostics and when working with the patients who at the stage of preliminary clinical and psychological conversation demonstrate the absence of distinct speech disorders.

If the testee adequately understands the speech addressed to him, shows the ability to take part in the conversation, the developers of the tests recommend starting the examination with the most complex specially selected tasks that allow identifying weakly expressed disorders of higher mental functions. Successful execution of such sensitized tests makes it unnecessary to perform simple tasks, which can reduce the time spent on testing.

The protocol of neuropsychological research includes a preliminary collection of general information about the patient (gender, age, education, marital status, profession), clarification of the anamnesis (heredity, etiological factors of the disease, the presence of craniocerebral trauma in the anamnesis, etc.), data from the clinical study (neurological, psychopathological). 
The study of speech functions allows identifying and evaluating the symptoms of disorders of various functional systems of speech.

When assessing expressive (productive) speech, the examiner considers the ability to speak spontaneously, take part in a dialogue, automated speech skills, the ability to produce a monologue, compose a story based on pictures, and compose sentences for a picture.

This section also includes examining the reflected speech, i.e. repetition of isolated sounds, syllables, words, a series of unrelated words and sentences of various lengths and syntactic complexity after the examiner. When performing the tasks presented in this section, the examiner fixes pronunciation features: prosodic characteristics of speech, the presence of self-corrections, false starts, perseverations, verbal and literal paraphasias, the ability to reproduce the names of objects in the testee's field of vision, parts of his body and objects depicted in pictures, the ability to name actions.

Significant parameters in the assessment of oral speech production are such factors as oligologia, the presence of agrammatisms, perseverations, echolalia, an increase in the latency period for recalling words, long pauses, the predominance of verbs or nouns in speech, replacement of significant parts of speech with substitute words, rude articulatory distortions. It is important to pay attention to the testee's reaction on the prompt in case of difficulty in recollecting the necessary words, the tendency to wordiness, the tempo of speech, intonation pattern, the replacement of lexemes with others belonging to the same conceptual group. Informative is the patient's attitude to disorders of his own speech, awareness of the presence of a defect.

Impressive speech (receptive speech skills) is tested through examining the understanding of individual words, commands, "situational speech". The examiner also tests the ability to retain a speech sequence perceived by ear. The comprehension of verbally presented complex logical-grammatical constructions (inflectional relations, etc.) is tested. In the same section, the authors of the method included the tasks for performing phonemic analysis of words (deter- mining the number of letters in words, determining the first and last sounds in words, etc.).

It is important to consider the differences in performing actions that are directly related to the situation in which the patient is (performing commands, discussion of the environment and the testee's condition) and tasks unmotivated by the situation, introduced into communication through speech or visual stimuli. Also, the examiner looks at the ability of the patient to switch from one task to others.

This is followed by a reading test, which includes tasks for recognizing and classifying letters, reading syllables, words and sentences, reading to oneself and following the written instructions, matching inscriptions and pictures, and reading short stories aloud.

When completing the tasks, the examiner looks at the ability to recognize letters written in different fonts and the text presented against a noisy background, reading tempo, the presence of literal and verbal paraphasias when reading aloud, the ability to follow the written instructions.

The next section is devoted to testing the writing skills. The examiner tests the ability to copy a text; write individual letters, syllables, words, sentences at dictation; compose words from a split alphabet, write independently. When evaluating writing skills, the examiner pays attention to the number and quality of errors (omission, replacement and rearrangement of letters).

After that, counting skills, praxis, and other skills are tested at the discretion of the examiner. Each item is rated on a scale from zero to three points. The results are visualized in graphs. The tests were supplemented with separate subtests aimed at identifying the dominant hand and functional asymmetry of the testee's cerebral hemispheres.

The Scenario Test was developed in the Netherlands, and the first results were published in 2010. The authors were I. van der Meulen, W.M.E. van de Sandt-Koenderman, H.J. Duivenvoorden, G.M. Ribbers (van der Meulen et al., 2010). The German version is currently being tested.

The test is designed to assess the communication ability of the patients with severe 
aphasia. The innovative nature of this test lies in the orientation towards multimodal communication, the use of not only verbal, but also compensatory non-verbal forms of interaction. When creating test assignments, emphasis was made on everyday communication situations. The testing procedure takes place in the form of interaction with a genuinely interested, supportive communication partner.

The test is part of a therapeutic work with the patient aimed at developing the skills of augmentative alternative communication (Jacobs et al., 2004). A person with severe speech disorders is trained to use the entire arsenal of non-verbal communication tools (gestures, drawing, communication notebooks) in order to provide an opportunity for interaction in everyday life. Thus, the test allows checking to what extent a person is able to send communicative messages using any available communication channels.

The patients with severe impairments of the mechanisms of understanding and speech production lose the ability to communicate independently. The success of interaction with them directly depends on the behavior of the communication partner, on his readiness for multimodal communication. This factor is crucial in the choice of test methods carried out exclusively in a dialogue format using a wide range of both residual verbal and non-verbal means (writing, drawing, gestures, etc.) with the provision of discursive support by the examiner.

The test includes 18 tasks representing 6 everyday situations for a Dutch resident (shopping, visiting a doctor, taking a taxi, meeting friends, communicating with a nurse, dinner at a restaurant). For example, the situation "In a restaurant" includes the following tasks: 1 . You and your friends are having lunch in a restaurant, you need to go to the toilet, how do you ask the waiter? 2. You want to see the menu, how do you ask to bring it to you? 3. You were served soup, but the spoon was not brought. What are your actions? When answering the third, for example, question, it is enough for the patient to make the "eat with a spoon" gesture to convey the message "I need a spoon". The examiner formulates the task orally, then the patient is shown a black and white picture representing the situation to facilitate understanding of the question. Next, the testee is asked to answer the question. If he finds it difficult, he is provided with communicative assistance according to the test procedure. Each answer is rated on a scale from 0 to 3 points. Three points are given if the testee was able to convey the key element contained in the question, without additional help, the message transmission channel does not play a role. If the testee needed help in switching to alternative communication channels, he was offered to show with a gesture, draw, etc. and after that he coped with the task, 2 points are given. If the testee cannot convey the message himself, but adequately answers the alternative "yes / no" questions, one point is given. If there was no answer in any form, including additional alternative questions, 0 point is given. The whole procedure is recorded on video, the score is given after watching it, which allows the examiner not to miss individual non-verbal contributions of the testee. The maximum number of points is 54. In addition to quantitative assessment, a qualitative analysis is carried out; as a result, it is noted which communication channel is preferable for the patient; how effectively the person uses this channel; ease of transition from one mode to another; the amount and quality of assistance provided by the communication partner; understanding everyday scenarios. This test allows formulating tasks for restorative communication training.

This test does not control the retention of speech function, but rather reveals the extent to which the patient with aphasia is able to compensate for the deficit of verbal communication with other forms of communication. It is applicable to assess progress in the work with the patients who receive the minimum score when using other diagnostic tests (for example, the Aachen Aphasia Test).

The protocol for the study of metalinguistic skills in the patients with aphasia (Protocolo de exploración de habilidades metalingüísticas naturales en la afasia (MetAphAs)) was developed at the University of Valencia. The results of the work of an interdisciplinary team that brought together the efforts 
of language psychology researchers, speech therapists and clinical linguists were published in 2014 (Clari, Sacristán, 2014).

This test allows assessing the retention of metacognitive functions in people suffering from aphasia and other disorders resulting from brain lesions of various etiologies.

The developers of the test believe that it allows to identify the safety of internal speech and factors that inhibit the process of converting it into external speech.

The protocol includes six sections:

1) control of the retention of internal speech, the ability for delayed speech;

2) testing the ability to use various modes of communication;

3) testing paraphrastic skills and related phenomena;

4) control of the ability to understand and reproduce someone else's (direct and indirect) speech;

5) assessment of the ability to control speech;

6) revealing the ability to discuss events that are not motivated by the situation.

The first section is devoted to the control of the retention of internal speech and the skill of delayed speech. It is presented in six tasks, including talking about the testee's thoughts at the examiner's request, folding puzzles with speech accompaniment of the activity, repeating the phrases in a whisper after the examiner, reading the text to oneself followed by a discussion of the content, answering the examiner's questions after a twenty-second pause, delayed (by 20 seconds) description of the recipe of the testee's favorite dish.

The second section is aimed at identifying the ability to simultaneously use various modes of communication. It includes tasks to hum the melody of a popular song, pronounce an emotionally intonated phrase, and reproduce, at the examiner's request, several statements with different intonation patterns. This section also includes an assessment of non-verbal communication tools used in all other tasks of the protocol, the frequency and appropriateness of the patient's use of discourse markers.

The third section consists of tasks to reveal the testee's ability to rephrase what has been said. It includes the following subtests: formulation of definitions for words denoting concrete objects and abstract phenomena; description of the purpose of the depicted items usage. At the same time the presence of paraphasias and the presence of nominative difficulties are tested.

The next section controls the ability to understand and reproduce someone else's (direct and indirect) speech. It includes the following subtests: the testee must convey the examiner's request to a third party; convey direct speech; take on the role of a fictional character and repeat after the examiner the lines of this character, imitating intonation and other prosodic characteristics; retell a read or heard narrative.

The fifth section reveals the ability to control speech. It includes the following tasks: dividing words into syllables; use of phrasal stress to highlight a specific word in a speech stream; acting out situations (talking on the phone, working with an answering machine, dialogue with a friend, etc.); deliberately committing an error in speech such as verbal or literal paraphasia; correction of errors in the speech of the interlocutor; completion of an unfinished phrase; evaluating the statements of the interlocutor.

The last section is devoted to identifying the ability to discuss events unmotivated by the situation. The tasks include description of a picture (the visual stimulus is removed after a minute presentation); description of the events that happened to the testee in the recent past (during the last week); discussion of the events that happened in the distant past (the testee's first place of work); discussion of the events that will happen in the future (plans for the next weekend); taking on the role of the character depicted in the picture and speaking on his behalf; naming antonyms; selection from a number of presented images of a person experiencing a certain emotion (fear, joy, etc.); composing sentences with given words; production of statements that do not correspond to reality; production of ironic statements.

Each subtest is rated on a scale from 0 to 4 points. In parallel with testing the patient, an accompanying person (relative) is interviewed. 
The MetAphAs test, according to its developers, can be used to assess the severity of aphasiac syndrome and diagnose various forms of aphasia, but its main purpose is to identify the relationship between metacognitive processes and human verbal behavior.

\section{Discussion and conclusions}

The presented review reveals a number of problems in the diagnosis of speech disorders associated with local brain lesions. Classifications of aphasiac disorders in different scientific schools dealing with the study of lesions of verbal thinking differ to a large extent. The problem of validating methods for detecting aphasias has not been resolved, "diagnostic algorithms are quite subjective and largely depend on the individual experience of the researcher, which significantly complicates the comparability and reproducibility of the results" (Wasserman et al., 1997: 30). The discrepancy between diagnostic methods can lead to discrepancies in the diagnosis, which is confirmed, in particular, by the data of a group of researchers who compared the results of using the Western Aphasia Battery and the Boston Aphasia Test (Wertz et al., 1984).

The neuropsychological tests that were developed in the $40 \mathrm{~s}-80$ s correlated with the lin- guistic data of the corresponding period. The developers of modern methods have the opportunity to use the achievements and the experience of clinical linguistics of the last decades. There are interdisciplinary areas such as neuropragmatics (Douglas, 2010; Büttner, 2017); studies of augmentative / alternative communication (Jacobs et al., 2004) and others which are actively developing.

Prospects for the development of diagnostics of speech localization in the brain obviously lie in the combination of methods of neuropsychology and neuroimaging (Korobkova et al., 2015), in the use of artificial intelligence. The frequency of cerebral stroke makes the interdisciplinary integration of doctors, neuropsychologists, speech therapists, linguists relevant to effectively overcome its consequences. In addition, a comparative analysis of test methods developed by the scientists and practitioners of different language cultures clearly reveals a culture-specific diagnostic marker in accordance with the research traditions of countries and the cognitive-mental characteristics of patients from different cultures. The solution of the problem of effective recovery of lost communication abilities is possible with combined interdisciplinary efforts of the specialists in various fields of knowledge.

\section{References}

Ardila, A., Akhutina, T.V., Mikadze, Yu.V. (2020). Vklad A.R. Lurii v izuchenie mozgovoi organizatsii iazyka [A.R. Luria's contribution to studies of the brain organization of language]. In Nevrologiia, neiropsikhiatriia, psikhosomatika [Neurology, neuropsychiatry, psychosomatics], 12(1), 4-12.

Büttner, J. (2017). Neuropragmatics - taxonomy of communication disorders and diagnostics in TBI [Neuropragmatik - Taxonomie von Kommunikationsstörungen und Diagnostik bei SHT]. In Aphasie und verwandte Gebiete. Aphasie et domaines associés, 1, 31-45.

Clari, V.R., Sacristán, C.H. (2014). The protocol for the study of metalinguistic skills in the patients with aphasia (MetAphAs) [Protocolo de exploración de habilidades metalingüísticas naturales en la afasia (MetAphAs)]. Valencia, Universidad de Valencia, Nau llibres, 165 p.

Douglas, J. M. (2010). Relation of Executive Functioning to Pragmatic Outcome Following Severe Traumatic Brain Injury. In Journal of Speech Language and Hearing Research, 53(2), 365-382. DOI: 10.1044/10924388(2009/08-0205)

Huber, W., Poeck, K., Weniger, D., Willmes, K. (1983). The Aachen Aphasia Test [Aachener Aphasie Test $(A A T)$ ]. Göttingen, Toronto, Zürich, Verlag für Psychologie, $153 \mathrm{p}$.

Jacobs, B., Drew, R., Ogletree, B. T., Pierce, K. (2004). Augmentative and Alternative Communication (AAC) for adults with severe aphasia: where we stand and how we can go further. In Disability and Rehabilitation, 26(21/22), 1231-1240. DOI: 10.1080/09638280412331280244 
Kadykov, A.S., Shakhparonova, N.V. (2013). Bol'noi posle insul'ta na prieme u nevrologa [Stroke patient seeing a neurologist]. In Medicinskii sovet [Medical Council], 6, 76-83.

Korobkova, L.A., Vlasova, R.M., Sinitsyn, V.E., Pechenkova, E.V. (2015). Nominatsiia ili artikuliatsiia: fMRT-issledovanie [Nomination and articulation: fMRI examination]. In E.V. Pechinkova, M.V. Falikman (Eds.) Kognitivnaya nauka v Moskve: novye issledovaniia [Cognitive Science in Moscow: New Research]. Moscow, 190-196.

Lauterbach, M., Pavão Martins, I., Garcia, P., Cabeça, J., Ferreira, A.C., Willmes, K. (2008). Cross linguistic aphasia testing: The Portuguese version of the Aachen Aphasia Test (AAT). In Journal of the International Neuropsychological Society, 14, 1046-1056. DOI: 10.1017/S1355617708081253

Luria, A.R. (1947). Travmaticheskaia afaziia. Klinika, semiotika i vosstanovitel'naia terapiia [Traumatic aphasia. Clinic, semiotics and rehabilitation therapy]. Moscow, Izdatel'stvo Akademii meditsinskikh nauk SSSR, 367 p.

Luria, A.R. (2021). Vysshie korkovye funktsii cheloveka [Higher cortical functions of a person]. St. Peterburg, Piter, 768 p.

Miller, N., Willmes, K., De Bleser, R. (2000). The psychometric properties of the English language version of the Aachen Aphasia Test (EAAT). In Aphasiology, 14:7, 683-722. DOI: 10.1080/026870300410946

Mozheiko, E.Yu. (2008). Vosstanovlenie rechevykh narushenii u postinsul'tnykh bol'nykh: aktual'nost', problemy i perspektivy [Recovery of speech disorders in poststroke patients: the urgency, problems and prospects]. In Sibirskoe meditsinskoe obozrenie [Siberian Medical Review], 2(50), 16-20.

Neuropsychological diagnostics (2007). - Neiropsikhologicheskaia diagnostika. Chast' 1. Skhema neiropsikhologicheskogo issledovaniia vysshikh psikhicheskikh funktsii i emotsional'no-lichnostnoi sfery [Neuropsychological diagnostics. Part 1. Scheme of neuropsychological research of higher mental functions and emotional-personal sphere]. (2007). Ed. by E.D. Homskaia. Moscow, Institut obshhegumanitarnykh issledovanii, 64 p.

Risser, A.H., Spreen, O. (1985). The western aphasia battery. In Journal of Clinical and Experimental Neuropsychology, 7:4, 463-470. DOI: 10.1080/01688638508401277

Tsvetkova, L.S. (1988). Afaziia i vosstanovitel'noe obuchenie [Aphasia and restorative teaching]. Moscow, Prosveshchenie, $207 \mathrm{p}$.

van der Meulen, I., van de Sandt-Koenderman, W.M.E., Duivenvoorden, H.J., Ribbers, G.M. (2010). Measuring verbal and non-verbal communication in aphasia: reliability, validity, and sensitivity to change of the Scenario Test. In International Journal of Language and Communication Disorders, 45, 424-435. DOI: $10.3109 / 13682820903111952$.

Wasserman, L.I., Dorofeeva, S.A., Meerson, Ya.A. (1997). Metody neiropsikhologicheskoi diagnostiki [Methods of neuropsychological diagnosis]. St. Petersburg, Stroylespechat, 360 p.

Wertz, R.T., Deal, J.L. Robinson, A.J. (1984). Classifying the Aphasias: A comparison of the Boston Diagnostic Aphasia Examination and the Western Aphasia Battery. In R.H. Brookshire (Ed.) Clinical Aphasiology Conference proceedings, 40-47. 


\title{
Тестирование когнитивных речевых расстройств: опыт европейской и российской клинической лингвистики
}

\author{
Н.Г. Бурмакина, Ю.И. Детинко, \\ Л.В. Куликова, Я.В. Попова \\ Сибирский федеральный университет \\ Российская Федерачия, Красноярск
}

\begin{abstract}
Аннотация. Статья посвящена проблеме патологии речевой деятельности, возникающей при локальных поражениях мозга, и анализу тестов, применяемых в европейских странах и в России для диагностирования афазических расстройств. Цель статьи - представить обзор методик, четыре из которых прошли значительную апробацию и широко применяются для тестирования речи пациентов с афазиями; три другие были созданы относительно недавно и отражают современное состояние прикладной клинической лингвистики, а также новые направления поиска эффективных нейролингвистических инструментов работы с людьми, страдающими распадом речевого мышления. Применяется описательный метод исследования. Типологии нарушений речевой деятельности, возникающих при повреждениях коры головного мозга, в европейских странах отличаются от принятых в российской традиции классификаций афазических расстройств. Отмечается, что существует проблема расхождений в постановке диагнозов при использовании различных методик. Очевидным является культурно-специфичный маркер диагностики в соответствии с исследовательскими традициями стран и когнитивно-ментальными особенностями пациентов, говорящих на разных языках. Современные подходы к работе с афазиями лежат в сфере нейропрагматики, исследовании метаязыковых умений и аугментативной / альтернативной коммуникации. Перспективы диагностики речевой локализации в мозге лежат в комбинировании методов нейропсихологии и нейровизуализации и в использовании искусственного интеллекта. Актуальность проблемы постинсультного распада механизмов речевой деятельности требует объединения усилий логопедов, лингвистов, неврологов, нейропсихологов.

Ключевые слова: клиническая лингвистика, афазия, методы нейропсихологической диагностики, аахенский афазиологический тест, западная афазиологическая батарея, тест-сценарий, протокол исследования металингвистических навыков при афазии, речевая реабилитация.
\end{abstract}

Научная специальность: 10.02.00 - языкознание. 